\title{
A case of anti-GBM nephritis following centipede bites and COVID-19 vaccination
}

\author{
Kei Nagai $^{1,2}$ (1) Mamiko Iwase $^{1} \cdot$ Atsushi Ueda $^{1}$
}

Received: 25 August 2021 / Accepted: 9 September 2021 / Published online: 15 September 2021

(C) Japanese Society of Nephrology 2021

\begin{abstract}
A case of newly developed anti-glomerular basement membrane (GBM) glomerulonephritis (GN) following centipede bites and COVID-19 vaccination is presented. A 70-year-old woman presented for investigation of mild fever, generalized fatigue, and macroscopic hematuria with no past history of renal disease. One year earlier, she had been bitten by a centipede. Based on the governmental policy, she was given the first COVID-19 vaccination, and the second injection was planned 3 weeks later. Accidentally, she was again bitten by a centipede, and the injured site had swollen severely. Based on a physician's judgment, the interval between vaccinations was extended to 8 weeks. One week after the second vaccination, macroscopic hematuria occurred suddenly, coincident with mild fever. Her serum anti-GBM titer was above the upper limit. There was no pulmonary involvement. Renal pathology showed anti-GBM GN, and she was treated with corticosteroid pulse therapy followed by sequential plasmapheresis. She had advanced renal dysfunction, but was independent of dialysis therapy during the one month of the remission induction therapy phase, and she is being treated with immunosuppressant therapy. Both vaccination and animal bites skew towards Th1 immunity, a key mechanism involved in the development of necrotizing GN evoked by anti-GBM antibody. Though there is no direct evidence for causality linking centipede bites, vaccination, and anti-GBM GN, the risk of anti-GBM GN appears to be increased by excessively induced Th1 immunity.
\end{abstract}

Keywords Rapidly progressive glomerulonephritis · COVID-19 - Vaccination · Delayed type hypersensitivity

\section{Introduction}

Administration of coronavirus disease 2019 (COVID-19) vaccination is a pressing need for controlling the worldwide pandemic. Generally, vaccination induces a variety of immunological reactions, particularly a Th1-dominant response [1]. Vaccination involves developing immunity to the viral antigen, but can trigger glomerular disease including nephrotic syndrome and glomerulonephritis [2]. Animal bites in adults often cause a delayed-type hypersensitivity reaction in the skin [3], showing locally proliferated interferon- $\gamma$ and tumor necrosis factor- $\alpha$-producing Th1-type effector lymphocytes. Both vaccination and animal bites

Kei Nagai

knagai@md.tsukuba.ac.jp

1 Department of Nephrology, Hitachi General Hospital, 2-1-1 Jonan-cho, Hitachi, Ibaraki 317-0077, Japan

2 Department of Nephrology, Faculty of Medicine, University of Tsukuba, 1-1-1 Tennodai, Tsukuba, Ibaraki 305-8575, Japan skew towards Th1 immunity, a key mechanism involved in the development of necrotizing glomerulonephritis (GN) evoked by anti-glomerular basement membrane (GBM) antibody in humans [4] and mice [5].

Recently, some reports suggested the possibility of gross macroscopic hematuria occurring following COVID-19 vaccination in patients with known $\operatorname{IgA}$ nephropathy $[6,7]$. Subsequently, there were two case reports of healthy individuals who presented with macroscopic hematuria shortly after COVID-19 vaccinations and were diagnosed with antiGBM GN $[8,9]$. Neither of them provides clear evidence of causality, but COVID-19 infection or other infectious complications that have the potential to trigger anti-GBM GN were ruled out. A case of gross hematuria with no prior renal disease that was diagnosed as newly developed anti-GBM GN following centipede bites and COVID-19 vaccination is presented in this report. 


\section{Case report}

A 70-year-old woman visited our hospital for investigation of her mild fever, generalized fatigue, and macroscopic hematuria with no history of renal disease (Fig. 1). One year earlier, she had been bitten on her right cheek by a centipede. Based on the governmental policy, she was given the first COVID-19 vaccination, and the second injection was planned 3 weeks later. Fourteen days after the first vaccination, accidentally, she was bitten again on her left finger by a centipede, and her whole forearm had swollen severely. Based on a physician's judgment, the interval between vaccinations was extended to 8 weeks. Nine days after the second vaccination, macroscopic hematuria occurred suddenly, coincident with mild fever. Her serum anti-GBM titer was above the upper limit and anti-neutrophil cytoplasmic antibodies were negative (Table 1). However, physical examinations and radiological investigations indicated that there was no pulmonary involvement. Though anti-nuclear antibody was positive as speckled and nucleolar staining patterns, no specific antibody in her serum was indicated as far as we examined. As her renal injury was obvious and rapidly progressive, we had started treatment with corticosteroid in advance of renal biopsy (Table 1 and Fig. 1). The renal specimen contained 16 glomeruli and global sclerosis was found only in two glomeruli. Glomerular tuft necrosis was frequently found (7 out of 14 non-sclerotic glomeruli) and three glomeruli had cellular crescents. No special findings were shown in arteriole and tubulointerstitial lesions.
Collectively, renal pathology demonstrated early phase of necrotizing GN with cellular crescents and infrequent global sclerosis (Fig. 2A, B). IgG and C3 were linearly deposited on the capillary wall, while $\operatorname{IgA}, \operatorname{IgM}$ and $\mathrm{C} 1 \mathrm{q}$ were not stained in glomeruli (Fig. 2C). On this basis, anti-GBM GN was diagnosed, and she was treated with corticosteroid pulse therapy and then sequential plasmapheresis 14 times. She had advanced renal dysfunction (minimum estimated glomerular filtration rate was $6.0 \mathrm{~mL} /$ $\min / 1.73 \mathrm{~m}^{2}$ ), but was independent of dialysis therapy during the 4 weeks of the remission induction therapy phase and while being treated with immunosuppressant therapy with intravenous cyclophosphamide (IVCY). As indicated by the decrease in C-reactive protein, systemic inflammation had been clearly attenuated after the initial treatment. Though hematuria and proteinuria partially remain, CY induced mild pancytopenia, and gamma globulin ( $\operatorname{IgG}$ $380 \mathrm{mg} / \mathrm{dL}$ ) was effectively suppressed. At 35 days after administration, her general status and daily activity are relatively good, and discharge is planned soon. IVCY will be administered several more times with short-term hospitalization.

\section{Discussion}

Currently, there seems to be no direct evidence for causality linking vaccination and anti-GBM GN in any reports [8-10]. In the same way, links between centipede bites and anti-GBM GN have generally not been demonstrated. In two reported cases of anti-GBM crescentic GN following

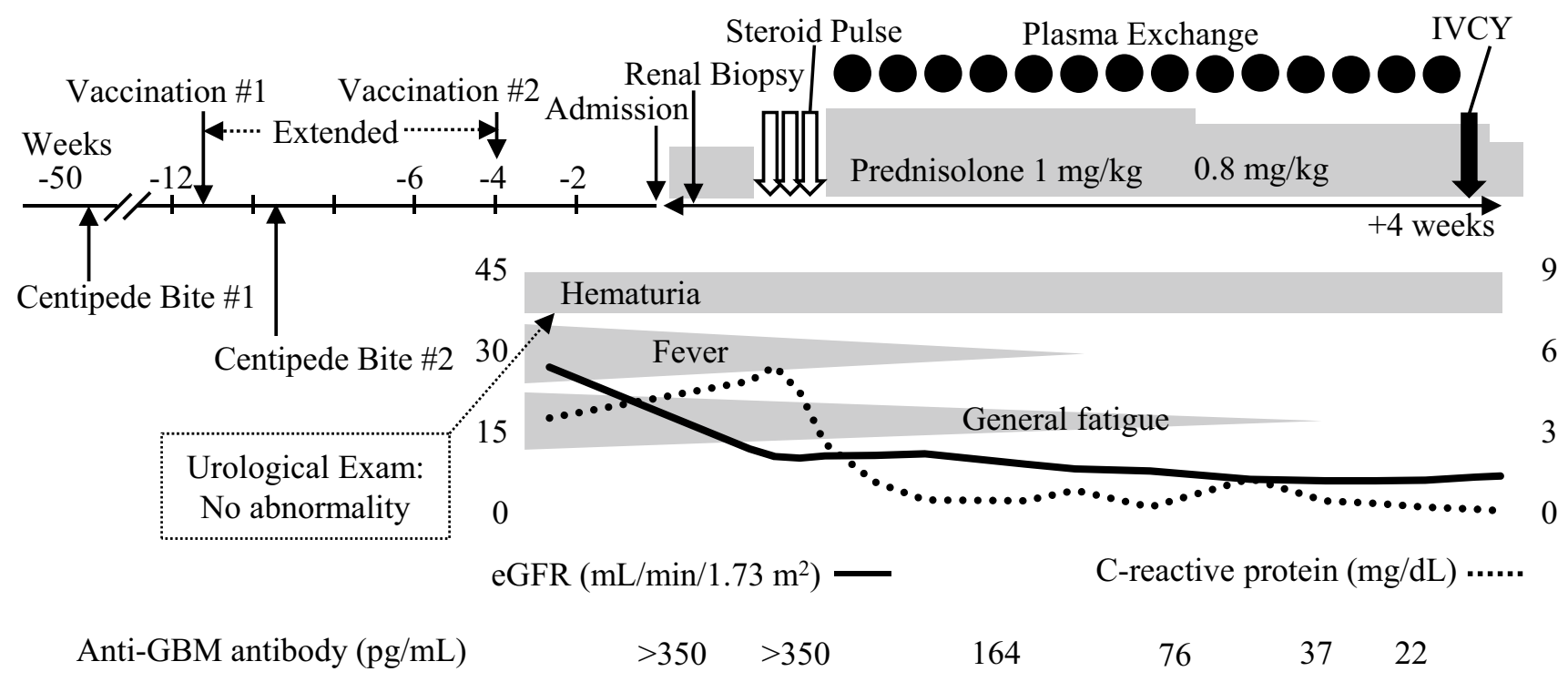

Fig. 1 Clinical course. Three weeks before admission, the patient developed macrohematuria, mild fever, and fatigue following two centipede bites and COVID-19 vaccination. She received steroid pulse therapy and high-dose oral corticosteroid, 14 sessions of plasma exchange, and intravenous cyclophosphamide (IVCY) 
Table 1 Laboratory finding on admission

\begin{tabular}{|c|c|c|c|}
\hline \multicolumn{2}{|l|}{ Urinalysis } & \multicolumn{2}{|l|}{ Blood chemistry tests } \\
\hline Gravity & 1.008 & Alkaline phosphatase & $68 \mathrm{U} / \mathrm{L}$ \\
\hline Protein & $3+$ & Creatine kinase & $70 \mathrm{U} / \mathrm{L}$ \\
\hline Sugar & Negative & HDL cholesterol & $149 \mathrm{mg} / \mathrm{dL}$ \\
\hline Blood & $3+$ & LDL cholesterol & $89 \mathrm{mg} / \mathrm{dL}$ \\
\hline Sediment & & Triglyceride & $95 \mathrm{mg} / \mathrm{dL}$ \\
\hline Red blood cells & $>100 / \mathrm{HPF}$ & Glucose & $105 \mathrm{mg} / \mathrm{dL}$ \\
\hline White blood cells & $1-4 / \mathrm{HPF}$ & Hemoglobin A1c & $5.0 \%$ \\
\hline Daily urinary protein & $1.8 \mathrm{~g} / 24 \mathrm{~h}$ & Serology & \\
\hline Bence Jones protein & Negative & C-reactive protein & $4.89 \mathrm{mg} / \mathrm{dL}$ \\
\hline Complete blood count & & HBs antigen & Negative \\
\hline White blood cells & $7800 / \mu \mathrm{L}$ & Anti-HCV & Negative \\
\hline Neutrophils & $69 \%$ & Immunoglobulin G & $1795 \mathrm{mg} / \mathrm{dL}$ \\
\hline Eosinophils & $2 \%$ & Immunoglobulin A & $510 \mathrm{mg} / \mathrm{dL}$ \\
\hline Basophils & $0 \%$ & Immunoglobulin $\mathrm{M}$ & $32 \mathrm{mg} / \mathrm{dL}$ \\
\hline Lymphocytes & $9 \%$ & Complement 3 & $115 \mathrm{mg} / \mathrm{dL}$ \\
\hline Monocytes & $20 \%$ & Complement 4 & $31 \mathrm{mg} / \mathrm{dL}$ \\
\hline Hemoglobin & $9.0 \mathrm{~g} / \mathrm{dL}$ & $\mathrm{CH} 50$ & $84.0 \mathrm{U} / \mathrm{mL}$ \\
\hline Platelets & $26.4 \times 10^{4} / \mu \mathrm{L}$ & Rheumatoid factor & $4 \mathrm{IU} / \mathrm{mL}$ \\
\hline Blood chemistry tests & & Anti-nuclear antibody & $\times 320$ \\
\hline Total protein & $6.2 \mathrm{~g} / \mathrm{dL}$ & Homogeneous & Negative \\
\hline Albumin & $2.9 \mathrm{~g} / \mathrm{dL}$ & Speckled & $\times 80$ \\
\hline Urea acid & $4.9 \mathrm{mg} / \mathrm{dL}$ & Nucleolar & $\times 320$ \\
\hline Urea nitrogen & $26.3 \mathrm{mg} / \mathrm{dL}$ & Peripheral & Negative \\
\hline Creatinine & $3.20 \mathrm{mg} / \mathrm{dL}$ & Discrete speckled & Negative \\
\hline Sodium & $142 \mathrm{mmol} / \mathrm{L}$ & Cytoplasmic & Negative \\
\hline Chloride & $103 \mathrm{mmol} / \mathrm{L}$ & PR3-ANCA & $<1.0 \mathrm{U} / \mathrm{mL}$ \\
\hline Potassium & $4.6 \mathrm{mmol} / \mathrm{L}$ & MPO-ANCA & $<1.0 \mathrm{U} / \mathrm{mL}$ \\
\hline Corrected calcium & $9.4 \mathrm{mg} / \mathrm{dL}$ & Anti-GBM antibody & $>350 \mathrm{U} / \mathrm{mL}$ \\
\hline Phosphate & $4.2 \mathrm{mg} / \mathrm{dL}$ & Anti-Scl-70 antibody & Negative \\
\hline Total bilirubin & $0.4 \mathrm{mg} / \mathrm{dL}$ & Anti-RNP antibody & $<2.0 \mathrm{U} / \mathrm{mL}$ \\
\hline Aspartate aminotransferase & $13 \mathrm{U} / \mathrm{L}$ & Anti-Sm antibody & $<1.0 \mathrm{U} / \mathrm{mL}$ \\
\hline Alanine aminotransferase & $8 \mathrm{U} / \mathrm{L}$ & Anti-SS-A antibody & $<1.0 \mathrm{U} / \mathrm{mL}$ \\
\hline Lactate dehydrogenase & $250 \mathrm{U} / \mathrm{L}$ & Anti-SS-B antibody & $<1.0 \mathrm{U} / \mathrm{mL}$ \\
\hline
\end{tabular}

$H D L$ high-density lipoprotein, $L D L$ low-density lipoprotein, $H B$ s hepatitis B surface, $H C V$ hepatitis $\mathrm{C}$ virus, $C H 5050 \%$ hemolytic unit of complement, $P R 3-A N C A$ proteinase-3-anti-neutrophil cytoplasmic antibodies, $M P O-A N C A$ myeloperoxidase-anti-neutrophil cytoplasmic antibodies, $G B M$ glomerular basement membrane, $R N P$ ribonucleoprotein, $S S$ Sjögren's syndrome
COVID-19 vaccination, one developed a day after the second dose [8] and the other 2 weeks after the second dose [9]. This time course, from a day to 2 weeks, but not hours, implies the involvement of delayed-type hypersensitivity in the development of GN. Since the effector T cell response to glomeruli should be antigen-specific, we hypothesized that either a centipede bite or an mRNA conjugated adjuvant might trigger the exposure of endogenous collagen or some molecular mimicry. Another explanation is that the Th1skewed condition uncovered potential genetic susceptibility to anti-GBM GN in the patient. It appears that either a centipede bite or COVID-19 vaccination alone may be insufficient, because no other case of anti-GBM GN has been seen in the usually vaccinated aged population so far in our region. Therefore, a lesson may be drawn from this unusual case: the risk of anti-GBM GN appears to be increased by excessively induced Th1 immunity.

The human leukocyte antigen (HLA) was further investigated to identify the intrinsic factor in this case of antiGBM GN by an external examination center (LSI Medience Corporation, Tokyo, Japan). HLA-DRB1*15:01 is known to be strongly associated with anti-GBM disease [11, 12], with autoreactive $\mathrm{CD}^{+}{ }^{+} \mathrm{T}$ cells against pathogenic epitope in type IV collagen [13]. The patient in the present report has HLA-DRB1*15:02, inconsistent with the previous cases since patients with anti-GBM disease are very likely to carry 
A

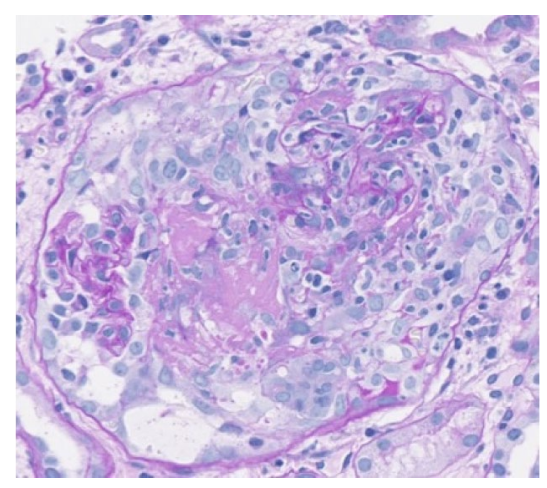

B

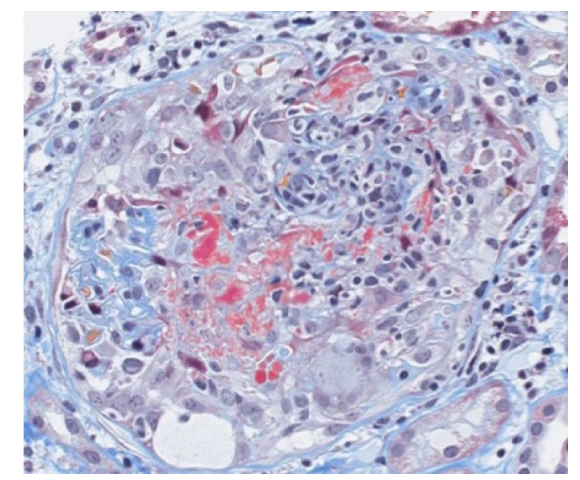

C

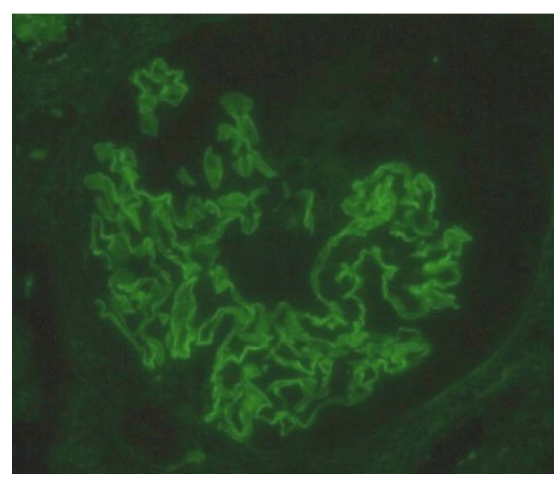

Fig. 2 Renal pathology. A-B. Focal crescentic glomerulonephritis is seen with necrotizing vasculitis, destruction of the glomerular tuft, and a cellular crescentic lesion (A. periodic acid-Schiff stain and $\mathbf{B}$.

the HLA-DRB $1 * 15: 01$, but not the HLADRB $1 * 15: 02$ allele [12]. In view of the molecular mechanisms, the only difference between DRB1*15:01 and DRB1*15:02 is the 86th amino acid: a valine residue in HLA-DRB1*15:01 is substituted by a glycine residue in DRB1*15:02 [12]. We are not convinced of the genetic involvement of HLA-DRB1*15:02 in the pathogenesis of the anti-GBM GN in the present case.

To the best of our knowledge, this is the first report of anti-GBM GN developing after centipede bites and COVID19 vaccination. We should be careful not to overlook newly developed progressive GN masked by common side effects of COVID-19 vaccination. Nevertheless, there is no doubt that vaccination is desirable and beneficial to attenuate the coronavirus pandemic and coincident anti-GBM GN induced by coronavirus infection [14].

Acknowledgements The authors would like to thank Tsuyoshi Tsukada and Kohei Inoue for their clinical support.

\section{Declarations}

Conflict of interest All the authors have declared no competing interest.

Informed consent Informed consent for publication was obtained from the patient described in this report.

\section{References}

1. Sahin U, Muik A, Derhovanessian E, et al. COVID-19 vaccine BNT162b1 elicits human antibody and TH1 T cell responses. Nature. 2020;586(7830):594-9. https://doi.org/10.1038/s41586020-2814-7 (Published correction appears in Nature. 2021 Feb; 590(7844):E17).

2. Abeyagunawardena AS, Goldblatt D, Andrews N, Trompeter RS. Risk of relapse after meningococcal $\mathrm{C}$ conjugate vaccine
Masson trichrome stain). C. Immunofluorescence shows linear deposition of IgG on the capillary wall compatible with anti-glomerular basement membrane glomerular nephritis

in nephrotic syndrome. Lancet. 2003;362:449-50. https://doi. org/10.1016/s0140-6736(03)14072-x.

3. Fung HT, Lam SK, Wong OF. Centipede bite victims: a review of patients presenting to two emergency departments in Hong Kong. Hong Kong Med J. 2011;17:381-5.

4. Ooi JD, Petersen J, Tan YH, et al. Dominant protection from HLA-linked autoimmunity by antigen-specific regulatory $\mathrm{T}$ cells. Nature. 2017;545:243-7. https://doi.org/10.1038/natur e22329.

5. Phoon RK, Kitching AR, Odobasic D, Jones LK, Semple TJ, Holdsworth SR. T-bet deficiency attenuates renal injury in experimental crescentic glomerulonephritis. J Am Soc Nephrol. 2008;19:477-85. https://doi.org/10.1681/ASN.2007030392.

6. Rahim SEG, Lin JT, Wang JC. A case of gross hematuria and IgA nephropathy flare-up following SARS-CoV-2 vaccination. Kidney Int. 2021;100(1):238. https://doi.org/10.1016/j.kint. 2021.04.024.

7. Negrea L, Rovin BH. Gross hematuria following vaccination for severe acute respiratory syndrome coronavirus 2 in 2 patients with IgA nephropathy. Kidney Int. 2021;99(6):1487. https://doi. org/10.1016/j.kint.2021.03.002.

8. Tan HZ, Tan RY, Choo JCJ, et al. Is COVID-19 vaccination unmasking glomerulonephritis? Kidney Int. 2021;100(2):46971. https://doi.org/10.1016/j.kint.2021.05.009.

9. Sacker A, Kung V, Andeen N. Anti-GBM nephritis with mesangial IgA deposits after SARS-CoV-2 mRNA vaccination. Kidney Int. 2021;100(2):471-2. https://doi.org/10.1016/j.kint.2021. 06.006.

10. Izzedine $\mathrm{H}$, Bonilla $\mathrm{M}$, Jhaveri KD. Nephrotic syndrome and vasculitis following SARS-CoV-2 Vaccine: true association or circumstantial? Nephrol Dial Transplant. 2021. https://doi.org/ 10.1093/ndt/gfab215.

11. Robson KJ, Ooi JD, Holdsworth SR, Rossjohn J, Kitching AR. HLA and kidney disease: from associations to mechanisms. Nat Rev Nephrol. 2018;14(10):636-55. https://doi.org/10.1038/ s41581-018-0057-8.

12. Kitagawa W, Imai H, Komatsuda A, et al. The HLA-DRB $1 * 1501$ allele is prevalent among Japanese patients with anti-glomerular basement membrane antibody-mediated disease. Nephrol Dial Transplant. 2008;23(10):3126-9. https://doi.org/10.1093/ndt/ gfn179.

13. Ooi JD, Chang J, O'Sullivan KM, et al. The HLA-DRB1*15:01restricted Goodpasture's T cell epitope induces GN. J Am Soc 
Nephrol. 2013;24(3):419-31. https://doi.org/10.1681/ASN. 2012070705.

14. Prendecki M, Clarke C, Cairns T, et al. Anti-glomerular basement membrane disease during the COVID-19 pandemic. Kidney Int. 2020;98:780-1. https://doi.org/10.1016/j.kint.2020.06.009.
Publisher's Note Springer Nature remains neutral with regard to jurisdictional claims in published maps and institutional affiliations. 